\title{
APORTES DE LUIS FERNANDO LARA A LA LEXICOGRAFÍA HISPANOAMERICANA EN $D E L A$ DEFINICIÓN LEXICOGRÁFICA ${ }^{1}$
}

\author{
Agustin Panizo Jansana
}

Luis Fernando Lara es una indiscutida autoridad en lexicografia hispánica y un antiguo critico de la lexicografia tradicional desarrollada en la RAE. Su vasta experiencia en la concepción y dirección de proyectos lexicográficos como el excelente Diccionario del Español Usual en México, lo ha llevado a reflexionar sobre aspectos teóricos que den sustento a sus planteamientos de método. Algunas de sus más recientes reflexiones en torno a la definición lexicográfica son reunidas en el pequeño volumen titulado De la definición lexicográfica ${ }^{2}$, que tiene el objetivo de retomar la discusión sobre la definición en el ámbito lexicográfico, habida cuenta de que, por un lado, en la filosofia, el problema de la definición aún no parece llegar a puerto seguro, y de que, por el otro, la práctica lexicográfica obliga al lexicógrafo a tomar decisiones que, bien miradas, constituyen también aseveraciones sobre la naturaleza de la definición, en este caso, la lexicográfica. El libro reúne seis textos correspondientes a ponencias o articulos antes publicados en diversos medios. En las líneas siguientes me dedicaré a reseñar y comentar su contenido.

\footnotetext{
Agradezco a Carlos Garatea sus valiosos comentarios a la versión preliminar de este texto.

Lara, Luis Fernando De la definicion lexicogyafica. Mexico, El Colegio de Mexico, $2004,182 \mathrm{pp}$.
} 
El primer articulo, publicado originalmente el 2002 en el compendio Lengua y diccionarios. Estudios ofrecidos a Manuel Seco, lleva por titulo "Autonimia", "mención" y sus consecuencias para el lenguaje lexicográfico». En este texto, el autor discute el principio filosófico del estructuralismo que, a partir de una lectura errónea de la afirmación de Saussure de que la lengua ues una totalidad en si y un principio de clasificación», otorgó a la noción saussureana de langue una existencia por ella misma, independiente "de las lenguas reales (de las que solo es su abstracción)" (2004: 16-17) y de las personas «que las hablan o que las utilizan para significar algo» (17). Lara considera, además, que una consecuencia de esa interpretación es el traslado de la noción de metalenguaje de los lenguajes cientificos a las lenguas naturales, y cuestiona el concepto que se propone como base: el signo autonimico, un signo "que se nombra o se refiere a si mismo y no a la experiencia del mundo que tiene una persona, como sucede al hablar de las cosas” (17).

Ante la paradoja del metalenguaje, que radica en que cada vez que un signo debe ser definido requiere de un salto a un nivel superior, a un nuevo metalenguaje, operación que se da sucesivamente, el lexicógrafo mexicano ofrece una alternativa de orientación pragmática al problema que lo ocupa: para él no hay signos autonímicos sino que «se trata siempre de casos de ostensión de un signo por un hablante o por un escritor, por los cuales los signos son solamente mencionados y no dejan de ser signos de la lengua naturals (22). En apoyo de su planteamiento, Lara recupera la distinción medieval entre uso y mención, la que "no está contenida en un complejo de relaciones entre lengua objeto y metalenguajes, sino que depende de quien la hace, es decir, de una persona que habla y busca reflexionar sobre los signos".

Entre las consecuencias de esta visión para la teoría lexicográfica (Lara rechaza la noción de metalexicografía), el autor señala que las entradas del diccionario no son "signos de si mismos" sino solo menciones, alternativa que encuentra su sustento mayor en la visión pragmática de la lexicografia,

Todas las citas textuales corresponden at mismo hibro (Lara 2004), por ho que en adelante incluiré solo los números de página, sin repetir el año. 
tantas veces defendida por Lara, según la cual el diccionario tiene su origen en un proceso natural a toda sociedad: ala pregunta y la respuesta acerca del signo, su uso y su significadon (28).

Visto asi, el diccionario es un simple compendio que reúne respuestas a la pregunta por el significado de las palabras, y nada más, no es por tanto un tratado cientifico que desentraña la esencia del significado de las palabras, no usa un riguroso metalenguaje al estilo de los lenguajes cientificos. En esto encontramos un gran valor en los planteamientos de Lara, pues hacen más sencilla la tarea de un lexicógrafo al despojarla de pretensiones que lo único que hacen es complicarla innecesariamente.

El segundo texto corresponde a una ponencia publicada el $2003 \mathrm{en}$ el volumen La lexicografía hispánica ante el siglo XXI. Balance y perspectivas bajo el titulo "El sentido de la definición lexicográfica". Aqui enfrenta Lara el problema de la definición lexicográfica, asunto que, visto de cerca, se presenta sumamente complejo. Dicha complejidad se hace más aguda cuando los lexicógrafos, por influencia de la filosofia positivista, buscan salidas formalistas que se ciñan a los rigores del positivismo. Lara rechaza esos descaminados intentos y propone una solución bastante simple al dilema: para él, una definición es sencillamente un "conjunto de proposiciones con que se explican y describen las características o cualidades de algo, sus rasgos y sus limites» (38). Estamos aqui entonces ante una concepción muy abierta de la definición lexicográfica, que ofrece relativa libertad al lexicógrafo y no le impone exigencias extrañas a las necesidades prácticas de su actividad: "la selección que hace un lexicógrafo de los tipos de definición que convienen al diccionario que se propone elaborar depende de la cuestión inicial de la lexicografia: para qué público escribe el diccionario y cuảles son sus necesidades en relación con el conocimiento del léxico de una lengua" (40). Nuevamente es la visión pragmática del diccionario la que nos orienta: las definiciones no son fórmulas estrictas que debe seguir el lexicógrafo para desentrañar un significado; las definiciones son respuestas a preguntas por el significado, y como tales dependen de quién pregunta -y quién responde-. Asi, las definiciones variarán según el caso. 
Hechas estas precisiones, Luis Fernando Lara presenta un problema al que volverá reiteradamente en los demás textos reunidos en este libro: la importancia de la concepción que profese el lexicógrafo acerca del signo lingüistico y la relación determinante que existe entre dicha concepción y el tipo de lexicografia que se desarrolle. «Se puede distinguir dos concepciones básicas: la nomenclaturista y la consustancialista” (41). La primera supone que "la palabra es solamente un soporte material de la referencia a un objeto o a la experiencia de vida, y que tal objeto o tal experiencia se articulan antes en las unidades mentales comúnmente llamadas conceptos, sin que intervenga la lengua” (41). Lara sostiene que es esta concepción la que origina que algunos lexicógrafos redacten definiciones enciclopédicas en diccionarios de lengua, definiendo cosas cuando debieran definir palabras, error ampliamente rechazado en la lexicografia reciente. La concepción consustancialista saussureana, a diferencia de la anterior, es defendida por el autor, pues permitiria la identificación de los varios significados de un signo lingüístico.

Seguidamente, Lara expone los cuatro tipos básicos de definición lexicográfica: nominal, explicativa, ostensiva y de uso. La nominal es la más adecuada para el caso de la terminología cientifica, pues "fija una convención designativa». La explicativa es la definición más común en lexicografia y atiende a los matices sutiles del significado para proponer un conjunto de informaciones resultado de una "reconstrucción del conocimiento histórico y cultural de la lengua». La definición ostensiva se entiende desde una perspectiva pragmática y es aquella que incluye información acerca del mundo sensible, información que puede facilitar al lector la comprensión del significado de voces como «azul», por ejemplo. Por último, la definición de uso es la más adecuada al momento de definir palabras de inventario cerrado, como las preposiciones, pues, como afirma Lara parafraseando a Wittgenstein, "su significado es su uso». Entre estos cuatro tipos de definición, el lexicógrafo deberá escoger la que mejor responda a sus necesidades puntuales para cada voz a definit.

El tercer texto recoje una ponencia leida en el XIV Congreso de la ALFAL de 2002 con el titulo. De la información a la cultura: dos sentidos de los diccionarios». Al discutir el primer sentido, según el cual 
el diccionario cumple una principal función informativa sobre la lengua, Lara vuelve al problema tratado en el texto anterior: la importancia de la concepción que tenga el lexicógrafo del signo lingüistico y de la forma en que la lengua sirve a la significación. Esta vez, las dos posibles concepciones del signo lingüistico son presentadas como (a) aquella que lo concibe como un simple "vehiculo material de la referencia", y (b) aquella para la cual el signo es una "unión indisoluble» de significado y significante. Como ha quedado ya claro en la teoria lexicográfica desarrollada por el autor, este se inclina por la segunda concepción, la saussureana, pues "Si las palabras tuvieran una función estrictamente designativa, y sólo valieran como soportes materiales de la referencia, el paso de [una palabra de una lengua a otra de otra lengua] debiera ser inmediato» (75), asunto cuya imposibilidad ilustra Lara con ejemplos del alemán y de diferentes dialectos del español.

En esta ponencia, Lara va un poco más allá del problema apenas expuesto y añade un aspecto derivado: el vinculo entre la concepción nomenclaturista del signo lingüístico y la relación asimétrica que existe entre la variedad peninsular y las demás variedades del español. El autor afirma que este nomenclaturismo "ofrece su principal sustento a la imposición prescriptiva de una sola variedad de la lengua sobre las demás: puesto que se postula la univocidad referencial del signo, uno de los vocablos concurrentes para nombrar el mismo objeto, la misma acción o el mismo concepto, y sólo uno de ellos, debe ser su nombre correcto y los demás simples dialectalismos, coloquialismos o jergalismos, a veces tolerados y otras perseguidos (80). Esta reflexión plantea un enfoque sumamente interesante, en la linea de sus criticas a la lexicografía prescriptivista de la RAE y a su tributaria contraparte: la "lexicografia hispánica del regionalismon. Lara es un conocido opositor de la lexicografia hispanoamericana que se concibe a si misma como apéndice del DRAE, como complemento regionalista pintoresco de la obra acadèmica, fenómeno para cuya comprensión aporta mucho el enfoque teórico presentado por el autor. En medio de una antigua tendencia a criticar el prescriptivismo peninsularista del DRAE, estos planteamientos de Lara se presentan mejor sustentados pues parten no de alegatos regionalistas sino de una sólida distinción teórica que podría resumirse 
asi: si las palabras son vistas simplemente como nombres para un mundo previamente organizado en conceptos, estos nombres son intercambiables y lo mismo da decir los nombres peninsulares o los regionales. Pero si las palabras, en cambio, son vistas como "unión indisoluble» de significado y significante, las voces regionales ya no son pintorescos equivalentes de las peninsulares, sino que tienen un valor mucho mayor. Esta concepción, en última instancia, pone en igualdad de condiciones a todas las variedades regionales del castellano.

Establecido, entonces, el camino que va "de la información a la cultura", Lara trata el segundo sentido del diccionario: "su papel como depósito de cultura». Superada la concepción nomenclaturista y abrazada la saussureana, como propone el autor, la lexicografia ya puede "penetrar en la densidad significativa del signo, que no solamente nombra objetos, acciones y experiencias de la realidad, sino que particulariza y matiza esa experiencia, de acuerdo con la manera en que cada cultura y cada civilización va construyendo su memoria colectivan (87). Estamos ante uno de los planteamientos fundamentales del lexicógrafo mexicano, quien lo presenta asi:

"Vistos desde esta perspectiva, los diccionarios son mucho más que obras informativas, en el sentido identificatorio y designatorio de la ciencia; son - o en muchos casos debieran ser-, obras de cultura, en donde la exploración del significado no sólo define lo que nombran los signos, sino sobre todo la manera en que se significa con ellos desde la experiencia historica de una cultura" (88).

Estas reflexiones llevan a Lara a plantear, siguiendo a Alain Rey, la necesidad de que un diccionario monolingüe exceda la austeridad informativa acostumbrada y se convierta en un diccionario cultural: "un diccionario donde cada articulo manifiesta dilatadamente la riqueza de los significados del vocablo a que está dedicado, atendiendo a los rasgos que explican sus matices" (89).

El cuarto texto es una ponencia leida el 2003 en el IULA de la Universidad Pompeu Fabra, Barcelona, bajo el nombre de "La definición 
falsificada”. Desde la primera oración de su texto, Lara establece con precisión su visión pragmática de la lexicografia: "La definición lexicográfica es una construcción interpretativa, no una determinación positiva y definitiva del significado de una palabra" (93). Y añade: "Como tal, está sujeta siempre al error que la falsifique» (93). La definición falsificada es, pues, toda definición errónea, que al presentarse en un diccionario se aparece al lector como verdadera, conduciéndole al error de interpretación.

Lara encuentra tres causas principales de error en la definición lexicográfica: (a) la procedente de la "concepción defectuosa o equivocada de lo que es un signo lingüistico", (b) "la que procede de errores de conocimiento o de información" y (c) la procedente de «una falla en el procedimiento hermenéuticon.

La primera causa se refiere al problema ya planteado en los artículos anteriores, pero que alcanza en este una explicación teórica un tanto mayor: el de la concepción nomenclaturista del signo lingüistico, señalada por Lara como causa "del tratamiento equivoco de la ecuación sémica y de la mala organización de las acepciones en el articulo lexicográficon (97). El error asociado a esta causa tiene que ver principalmente con la suposición de que se puede definir una voz con otras que se presentan como equivalentes, pasando por alto su particularidad semántica. La segunda causa de error es sumamente frecuente y el autor la ilustra con abundantes ejemplos de definiciones falsificadas ya sea porque incluyen información errónea o porque la información proporcionada es insuficiente o poco pertinente. La tercera causa deriva de «la propia identidad cultural del lexicógrafon y se refiere a aquellas definiciones en las que se han filtrado concepciones ideológicas. La recomendación de Lara es que «El lexicógrafo debe ser capaz de someter a crítica la ideología en que puede haber sido educado, para ofrecer una definición verdadera" (109). Contrariamente a lo que se podria suponer, Lara no propone aqui pasar todas las definiciones por un filtro de racionalidad, -tendencia que comprobamos en innumerables definiciones de estilo excesivamente formal que, lejos de presentar el significado de una voz, lo que hacen es despojarla de él y presentarla desde una perspectiva que las aisla de su propio ámbito de sentido-. Un ejemplo: según Lara, decir de la voz gnomo 
que significa un eser fantásticon no es apropiado, pues esta calificación racionalista no forma parte del significado de la voz, precisión que resulta sumamente adecuada si imaginamos, como hace él, a un niño leyendo el cuento de Blancanieves: el niño no necesita la precisión racionalista, sino solo saber que se trata de un "genio de las minas, guardián de los tesoros, de poca estatura, dotado de diversos poderes» (113). Puestos a considerar definiciones de elementos religiosos, creencias o mitologias americanas, por ejemplo, estas precisiones de Lara adquieren capital relevancia, y obligan a replantear muchas de las definiciones que encontramos en diccionarios de todo tipo.

Una ponencia presentada el 2003 en la Universidad de Regensburg, Alemania, constituye el quinto texto que compone este libro. En "La descripción del significado del vocabulario no-estándar", Lara comienza comentando el concepto desarrollado por Circulo de Praga de lengua literaria: construcción social dentro de una lengua histórica que se caracteriza por la ampliación e intelectualización de su léxico, el incremento de su flexibilidad sintáctica, la fijación de su escritura y la normalización de su uso. De este concepto surge el de lengua estándar y, en oposición, las lenguas no-estándar: conjuntos de tradiciones verbales mayoritariamente orales que carecen de un rico vocabulario intelectualizado, tienen un número limitado de patrones sintácticos y no se norman explicitamente sino "mediante oscuras y complejas normas implicitas en las sociedades que las hablan». Las lenguas no-estándar nacen de la vida diaria de los pueblos y corresponden a sus diversas tradiciones culturales, de ahi su importancia. Por ello, lejos de una valoración negativa derivada de su comparación con las estándar, las variedades no-estándar requieren ser objeto de una exhaustiva descripción lexicográfica.

Llegado a este punto, Lara se propone analizar cuatro elementos usuales en las definiciones de vocablos no-estándar: las marcas de uso, el lenguaje de la descripción, la definición y los ejemplos de uso. Las marcas de uso plantean los problemas de la sistematización del funcionamiento de las variedades y de la amplia documentación de usos reales. Sobre el lenguaje de la descripción, el autor reitera que se trata de un lenguaje estándar ordinario y no de un metalenguaje, y aborda 
el problema de la pretensión de intercambiabilidad entre voz definida y perifrasis sinonimica correspondiente: «El vocabulario no-estándar, en cuanto tradición verbal de la cultura hispánica popular, gana su valor precisamente de su capacidad significativa y por eso no tiene una versión equivalente en el vocabulario estándar” (132). Sobre la definición señala Lara que "tiene por objetivo una reconstrucción lo más exacta posible de todos los elementos de significación que dan al vocablo su valor único. Por eso la descripción a base de series cuasi-sinonimicas o, aun peor, a base de una sola palabra de la lengua estándar es una mala manera de lograr la descripción del significadom (138). Y, por último, sobre los ejemplos de uso, señala el autor que «la descripción se completa con indicaciones precisas y abiertas de las colocaciones del vocablo en su contexto sintáctico común y con ejemplos del uso real de la palabra» (139), cerrando el conjunto de recomendaciones técnicas de esta ponencia, que tienen su mayor valor, a diferencia de planteamientos de otras escuelas, en que están totalmente integradas con una fundamentación teórica medular que a partir de una manera de entender la lengua y los diccionarios deriva en un método lexicográfico sólido y versátil.

Un sexto texto cierra el volumen. Se trata de "Una hipótesis cognoscitiva sobre el orden de acepciones", articulo publicado originalmente en 1999 en el Boletín de Filologia en homenaje a Ambrosio Rabanales. En este texto, Luis Fernando Lara hace una revisión de los métodos tradicionalmente utilizados para ordenar las acepciones en un diccionario: el etimológico, el histórico, el de uso y el «lógico». El primero supone "una prioridad lexicográfica de la genealogia de las lenguas" y es una herencia de la lexicografia multilingüe de las lenguas romances. El método histórico se aparta del anterior al basarse en la evidencia del registro documental. El método de uso, por su parte, nace de la influencia de la lingüistica descriptiva y hace uso de evidencia de frecuencia para ordenar las acepciones. El cuarto método, aunque es llamado «lógico", no tiene que ver con la lógica en sentido estricto sino únicamente con la suposición de que existe un "significado principal" de cada vocablo y una serie de "significados emparentados" de alguna manera con aquel. Lara discute la validez de cada uno de estos métodos y los va descartando, hasta quedarse con el único que hace referencia a criterios internos de la 
lengua, el "lógico", para, a partir de este último, desarrollar un método que él llamará "cognoscitivo".

Para su planteamiento, Lara parte de la constatación hecha en los sesentas por Casagrande, Hale y Riegel de que "todo hablante es capaz de ofrecer una definición espontánea de cualquier vocablo, y que esa definición espontánea se hace sobre el significado que se presenta a la memoria individual como el más inmediato» (151). Este significado más inmediato, señala Lara, es «denominativo de algún objeto o de alguna acción del mundo experimentado" y es resultado de un «modo nominativo de significación» que es privilegiado por el hablante de cualquier origen cultural entre otros modos de significar la experiencia. Luego, el autor explora los hallazgos de la psicologia moderna para dar con la idea de prototipos, como «esquemas de reconocimiento e identificación de objetos y acciones del mundo sensiblem, los cuales, dada su dependencia de características fácticas de los objetos de conocimiento, son «relativamente indiferente[s] a la comunidad lingüistica y cultural a la que pertenezca [el individuo]" (153). Ante estos elementos, de naturaleza no verbal, Lara presenta los estereotipos, de naturaleza verbal y, por lo tanto, cultural y social: «El prototipo [...] forma su base, pero el significado se gesta socialmente: constituye lo que el filósofo angloamericano Hilary Putnam llama estereotipow (155). Presentada esta noción de estereotipo, el lingüista mexicano señala que las definiciones espontáneas de que hablaban Casagrande, Hale y Riegel son precisamente definiciones del estereotipo: este seria el «significado principal», de donde se sigue que el orden lógico de las acepciones deriva efectivamente de la naturaleza semántica de las palabras y no es un simple método lexicográfico.

Finalmente, Lara presenta resultados de una investigación que lo llevan a afirmar que no existe diferencia fundamental entre las respuestas que da un individuo cualquiera cuando es preguntado por las acepciones de una palabra y las respuestas que da un lexicógrafo al mismo requerimiento, lo cual se debe a que el orden de acepciones es de carácter cognoscitivo y se produce cuando una persona necesita "generar un dispositivo de interpretación de significados variados de un vocablo. (164). 
Concluida la lectura del conjunto de textos que componen este volumen, queda claro que los planteamientos de Luis Fernando Lara descansan sobre dos pilares teóricos fundamentales. El primero tiene que ver con la opción por el consustancialismo y el rechazo del nomenclaturismo en la concepción de la naturaleza del signo lingüistico, y con las amplias consecuencias benéficas de esta opción en el trabajo lexicográfico. El segundo es la defensa de una visión pragmática de la lexicografía. Ambos pilares teóricos no solo subyacen a los textos reunidos, sino que son expresa y reiteradamente expuestos en estos. Ambos pilares teóricos constituyen, además, excelentes sustentos que aclaran nuestro acercamiento al objeto diccionario y nos convocan con mayor seguridad a la prácrica de su confección.

Ante una lexicografia hispanoamericana que se ha desarrollado con desigual rigor y no pocos desaciertos, el ejemplo de México, con Luis Fernando Lara como su principal impulsor, constituye sin lugar a dudas un potente faro que señala una ruta a seguir para una nueva lexicografía concebida desde América. El caso particular del Perú reclama desde hace mucho un diccionario ambicioso, que emprenda la acertada descripción de la memoria colectiva que desde antiguo ha venido siendo construida por los pobladores de este trozo de América. Hoy más que nunca está claro que esta tarea requiere del concurso de los lingüistas, quienes, acostumbrados a ver los diccionarios como ajenos a la realidad e imperfectos en su aproximación al léxico nacional, han desestimado su relevancia y visto por encima del hombro el quehacer que los gesta. La tarea es ardua pero el estimulo es potente y hoy tenemos especialistas trabajando en proyectos interesantes. El panorama, por tanto, es auspicioso, y bueno seria que en él las valiosas recomendaciones de Luis Fernando Lara expuestas en las pảginas precedentes hallaran una reflexiva acogida. 